\title{
DESIGN, SYNTHESIS, DOCKING, ANTITUMOR SCREENING, AND ABSORPTION, DISTRIBUTION, METABOLISM, AND EXCRETION PREDICTION OF NEW HESPERDIN DERIVATIVE
}

\author{
HANADY S AL-SHMGANI ${ }^{1}$, RAIED MUSTAFA SHAKIR ${ }^{1}$, AHMED W NASER ${ }^{2}$, OLUSOLA OLALEKAN ELEKOFEHINTI ${ }^{3}$
}

${ }^{1}$ Department of College of Education for Pure Science Ibn Al-Haitham, University of Baghdad, Iraq. ${ }^{2}$ Department of College of Science, University of Baghdad, Iraq. ${ }^{3}$ Department of Biochemistry, Bioinformatics and Molecular Biology Unit, Federal University of Technology, Akure, Ondo State, Nigeria. Email: hanadysalim@yahoo.com

Received: 20 September 2019, Revised and Accepted: 31 November 2019

ABSTRACT

Objective: Hesperidin (HSP) is a pharmacologically active organic compound found in citrus fruits and peppermint. We synthesized a new HSP derivative by reacting it with 5-Amino-1,3,4-thiadiazole-2-thiol in acetic acid.

Methods: This compound was characterized by Fourier-transform infrared, proton nuclear magnetic resonance, and electron impact mass spectra. A molecular docking study explores the predicted binding of the compound and its possible mode of action. Bioavailability, site of absorption, drug mimic, and topological polar surface was predicted using absorption, distribution, metabolism, and excretion (ADME) studies.

Results: The docking study predicts that the new compound binds to the active sites of Aurora-B and the MST3 pocket and has good ADME properties. Moreover, the thiazole ring and the presence of the electron releasing groups and hydrogen bond interaction with amino acid residues within the active sites play an important role in enhancing the antioxidant activity.

Conclusion: In the present study, a new HSP derivative has been synthesized and characterized successfully and a theoretically promising antioxidant and anticytotoxic active agent introduced. We have shown the detailed binding analysis of 1,3,4-thiadiazol and hydrogen bonds with the inhibitor binding cavity of Aurora B and MST3. This could provide the development of some effective compounds against different diseases.

Keywords: Hesperidin derivative, Molecular docking, Absorption, distribution, metabolism, and excretion, Aurora B.

(C) 2020 The Authors. Published by Innovare Academic Sciences Pvt Ltd. This is an open access article under the CC BY license (http://creativecommons. org/licenses/by/4. 0/) DOI: http://dx.doi.org/10.22159/ajpcr.2020.v13i1.35684

\section{INTRODUCTION}

Flavonoids are produced by plant secondary metabolism, typically as glycosides [1]. The antioxidative activity of flavonoids is associated with conjugated double bonds and the presence of functional groups in the rings [2]. Flavonoids are very potent in quenching free radicals and reduce their production. Hesperidin (HSP) is a glycoside flavone found mainly in citrus fruit peel, with diverse pharmacology activities including prostaglandin-synthesis inhibition, antioxidant, antiinflammatory, and anticancer effects [3-5]. HSP and maybe other natural flavonoids have lower water solubility and slight lipophilic molecules to effectively enter membrane [6,7]. Thus, a novel HSP derivative was designed and synthesized to address these shortcomings.

Recently, 1,3,4-thiadiazole derivatives exhibited biological effects such as antitumor, anti-inflammatory, antioxidant, and antimicrobial activity [8-10]. In the present study, a new derivative of HSP was synthesized by reacting with hydrazine derivatives to form the respective analogs.

\section{METHODS}

All the reagents are Laboratory grade and the solvents were analytic grade. All chemicals were obtained from Sigma-Aldrich (St. Louis, Mo, USA) and Merck (Darmstadt, Germany).

\section{Reagents}

Chemistry

General

The purity of the recrystallized compound was determined using thin-layer chromatography (TLC), and the structure was confirmed using physical properties and spectral analysis. The melting point was detected by open capillary tube method utilizing OMEGA MPS10 apparatus. The IR spectra were recorded by PerkinElmer 400 Fouriertransform infrared (FTIR) spectrometer. The proton nuclear magnetic resonance ( ${ }^{1} \mathrm{H}-\mathrm{NMR}$ ) spectra were recorded on Bruker AVN $300 \mathrm{MHz}$ (AL-Bayt University, Jordan), using dimethyl sulfoxide (DMSO- $\mathrm{d}_{6}$ ) as a solvent and tetramethylsilane as internal standard. The electron impact mass spectrometry (EIMS) was screened by Shimadzu gas chromatography-mass spectrometer-QP2010 Ultra (Al-Mustansiriyah University, College of Science, Department of Chemistry).

General procedure for the synthesis of HSP 1,3,4-thiadiazole-2-thiol A solution of 5-Amino-1,3,4-thiadiazole-2-thiol ( $0.61 \mathrm{~g}, 1 \mathrm{mmol})$ in methanol ( $5 \mathrm{~mL}$ ) was added drop-wise to hot stirring solution of HSP $(0.133 \mathrm{~g}, 1 \mathrm{mmol})$ in classical acetic acid $(10 \mathrm{~mL})$. The mixture was left under reflux for $18 \mathrm{~h}$ and monitored by TLC (chloroform:methanol 1:1). On cooling, the precipitate was collected and washed with distilled water. The crude product was recrystallized from aqueous dimethylformamide to afford white amorphous yield $78 \% \mathrm{mp} 219-221^{\circ} \mathrm{C}$. FTIR-IR (KBr, v max $\left./ \mathrm{cm}^{-1}\right)$; $3415(\mathrm{OH}), 2942,2874\left(\mathrm{CH}_{\text {Aliphatic }}\right), 2553(\mathrm{SH}), 1627(\mathrm{C}=\mathrm{N})$, 1596, $1583(\mathrm{C}=\mathrm{C}),{ }^{1} \mathrm{H}-\mathrm{NMR}$ (400 MHz, DMSO-d6) $\delta$, ppm; 1.065(dd, $3 \mathrm{H}, \mathrm{CH}_{3}$ ), 2.75 (ddd, $\left.1 \mathrm{H}, \mathrm{CH}\right), 3.09-3.26\left(\mathrm{~m}, 2 \mathrm{H}, \mathrm{CH}_{2}\right), 3.34-3.43(\mathrm{~m}, 6 \mathrm{H}$, $\left.3 \times \mathrm{CH}_{2}\right), 3.50-3.53(\mathrm{~m}, 1 \mathrm{H}, \mathrm{CH}), 3.61-3.62(\mathrm{~m}, 1 \mathrm{H}, \mathrm{CH}), 3.75-3.78(\mathrm{~m}$, $5 \mathrm{H}, \mathrm{OCH}_{2}$ and $\left.\mathrm{OCH}_{3}\right), 4.51(\mathrm{~d}, 1 \mathrm{H}, \mathrm{CH}), 4.96(\mathrm{t}, 1 \mathrm{H}, \mathrm{CH}), 5.14(\mathrm{dd}, 1 \mathrm{H}$, $\mathrm{CH}), 5.36(\mathrm{~d}, 1 \mathrm{H}, \mathrm{CH}), 5.48-5.49(\mathrm{~m}, 1 \mathrm{H}, \mathrm{CH}), 6.1-6.12(\mathrm{~m}, 2 \mathrm{H}, \mathrm{Ar}-\mathrm{H})$, 6.87-6.94 (m, 3H, Ar-H), 9.06 (bs, 1H, OH), 9.07 (bs, 1H, OH). EIMS, m/z $725\left[\mathrm{M}^{+}\right.$] (calc. for $\mathrm{C}_{30} \mathrm{H}_{35} \mathrm{~N}_{3} \mathrm{O}_{14} \mathrm{~S}_{2}, 725.16$ ), 413 [base peak (100\%) for $\left.\mathrm{C}_{19} \mathrm{H}_{15} \mathrm{~N}_{3} \mathrm{O}_{4} \mathrm{~S}_{2}^{\cdot+}\right]$.

Absorption, distribution, metabolism, execration, and toxicity (ADMET) and carcinogenicity study

In silico modeling of the HSP synthesized compound was done to predict the ADMET properties by ADMET online software, which is one of drug 
transport predictor and bioavailability [11]. These descriptors include human intestinal absorption, solubility of each compound in water at $25^{\circ} \mathrm{C}$ along with blood-brain barrier (BBB), and cytochrome p450-2D6 (CYP2D6) enzyme inhibition and plasma protein.

\section{Premetabolism and permeability study}

Molinspiration (MiLog P) was used to check drug permeability through cell membrane. Hydrophilic/lipophilic property of the drug is important in absorption, drug-receptor interaction, metabolism, and toxicity. Most molecules and drugs must pass across the liver microsomal enzymes and be metabolized. Molinspiration drug-likeness score online [12] was used to check drug bioactivity. Another key property linked to drug bioavailability is the total polar surface area (TPSA), which is connected with hydrogen bonding probable of molecule. The correlation of anticancer (as apoptosis inducers) was a good predictor of the affiliation between the lipophilicity of the newly synthesized

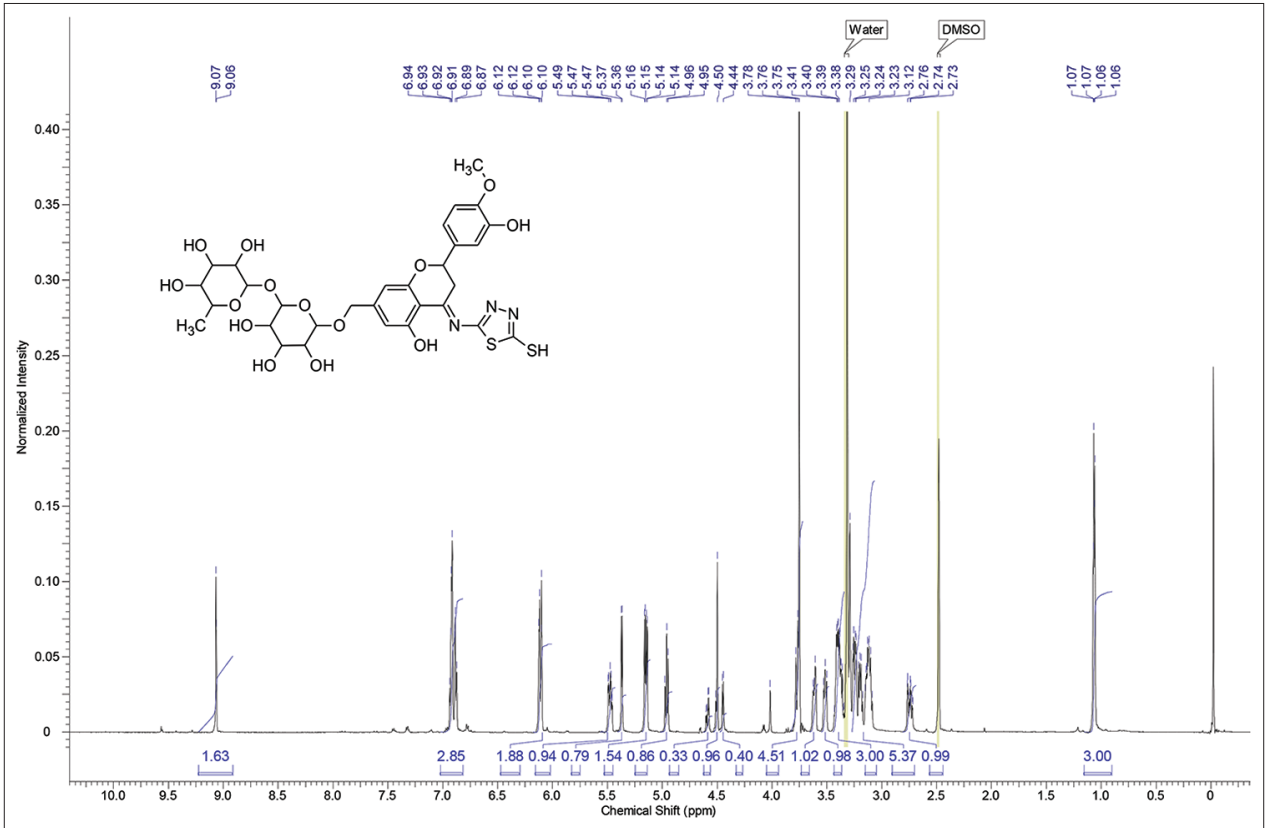

Fig. 1: Proton nuclear magnetic resonance (300 MHz, dimethyl sulfoxide- $\left.d_{6}\right)$ spectrum of synthesized compound<smiles>COc1ccc(C2CC(=O)c3c(O)cc(COC4OC(COC5OC(C)C(O)C(O)C5O)C(O)C(O)C4O)cc3O2)cc1O</smiles><smiles>Nc1nnc(S)s1</smiles>

\section{$\mathrm{AcOH}$}

\section{reflux $18 \mathrm{hs}$}<smiles>COc1ccc(C2C/C(=N\c3nnc(S)s3)c3c(O)cc(COC4OC(COC5OC(C)C(O)C(O)C5O)C(O)C(O)C4O)cc3O2)cc1O</smiles>

Scheme 1: route of synthesized newly compound 
Table 1: Carcinogenicity prediction of the synthesized compound

\begin{tabular}{lllllll}
\hline Compound & Ames test & Carcinogen on mouse & Carcinogen on rat & Carcinogenicity & HERG inhibitor & TA100-NA \\
\hline $\begin{array}{l}\text { Hesperidin } \\
\begin{array}{l}\text { Hesperidin } \\
\text { derivative }\end{array}\end{array}$ & Non-mutagen & Negative & Negative & 0 & Inhibitor & Negative \\
\hline
\end{tabular}

Carcinogen: 1 may be, Non carcinogen: 0. HERG: Human ether-a-go-go-related gene

Table 2: Predicted ADMET for the designed compound

\begin{tabular}{lllllll}
\hline Compound & BBB level & HIA & Cyt. P450 3A4 & CYP2D6 & PPB & Solubility level \\
\hline 1 & 0.03 & 9.88 & 0 & 0 & 43.45 & 2 \\
2 & 0.26 & 5.47 & Inhibitor & 0 & 70.09 & 2 \\
\hline
\end{tabular}

Solubility level: (4) High sol., (3) and (2) intermediate sol., (1) less sol., (0) poor sol. BBB: Blood-brain barrier, PPB: Plasma protein binding, CYP2D6: Cytochrome p450-2D6, HIA: Human intestinal absorption, ADMET: Absorption, distribution, metabolism, execration, and toxicity
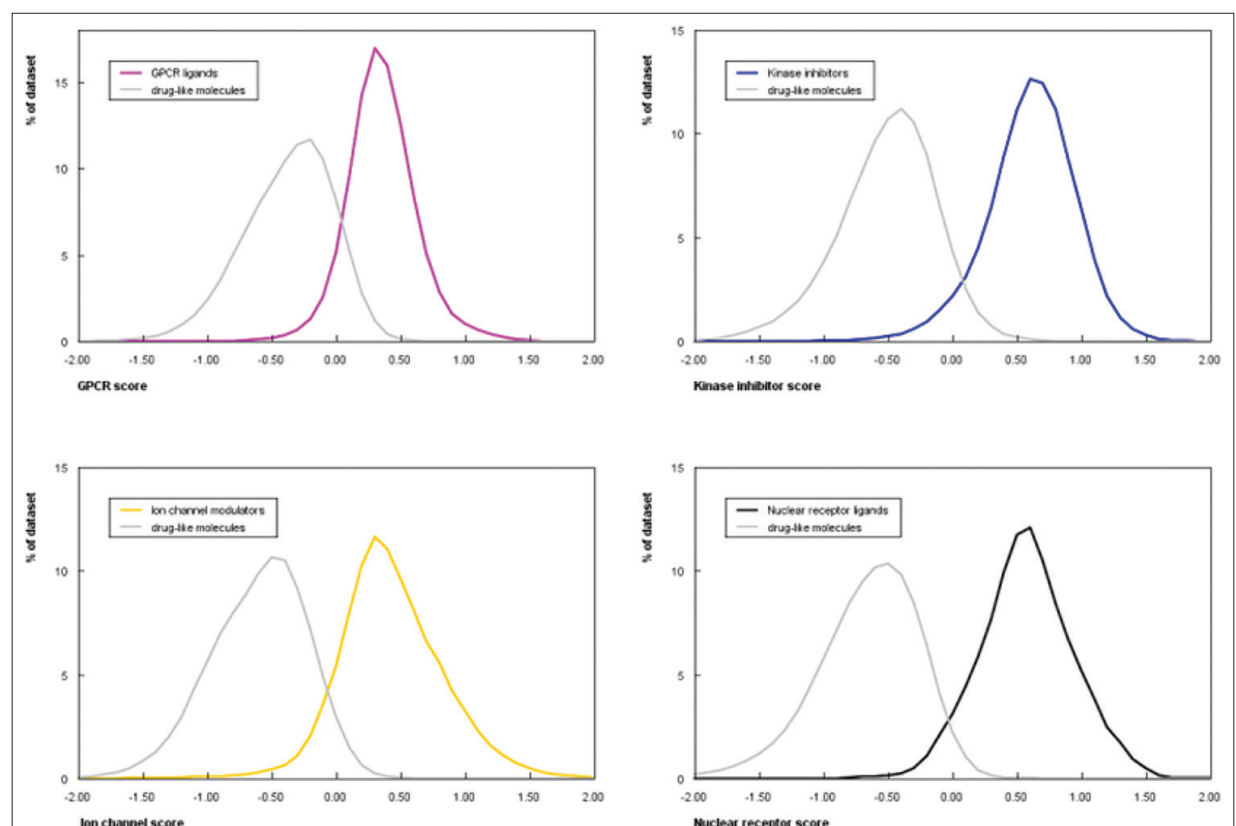

a
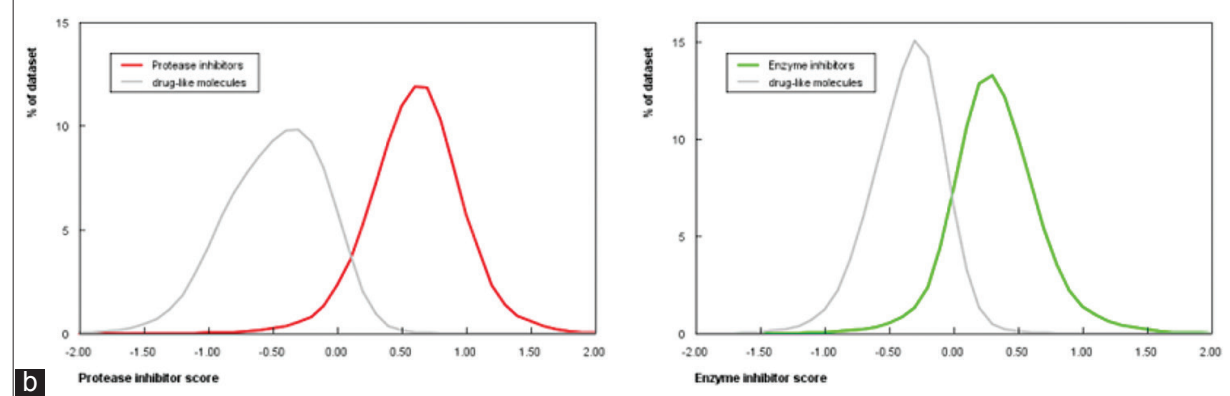

b

Fig. 2: (a and b) The bioactivity score of hesperidin derivative for different proteins

compound and their biological activities. The $\mathrm{C} \log \mathrm{p}$ value expresses the degree of the chemical compound.

\section{Molecular docking study}

Molecular docking study was carried out to provide discernments into the molecular binding types of the synthesized compound inside the pocket of Aurora-B protein and MST3 protein target site using MOE 2015 software. The binding sites were produced from the cocrystallized ligand contained by crystal protein (Protein Data Bank codes: 2BFY and 4QMT), respectively.
First, water molecules were removed from the complex followed by crystallographic disorders and unifilled valence atoms were adjusted using protein report and clean protein options. Protein energy was reduced by setting CHARMM and Merck Molecular Force Field 94 force fields. The rigid binding site structure of protein was found by setting a fixed atom control. The essential amino acid was definite and prepared for docking process.

ChemBioDraw Ultra 14.0 was used to outline two-dimensional structure of compound, and saved in Molecular Design Limited-Structure Data file 
Table 3: The effect of liver microsomal enzymes on hesperidin

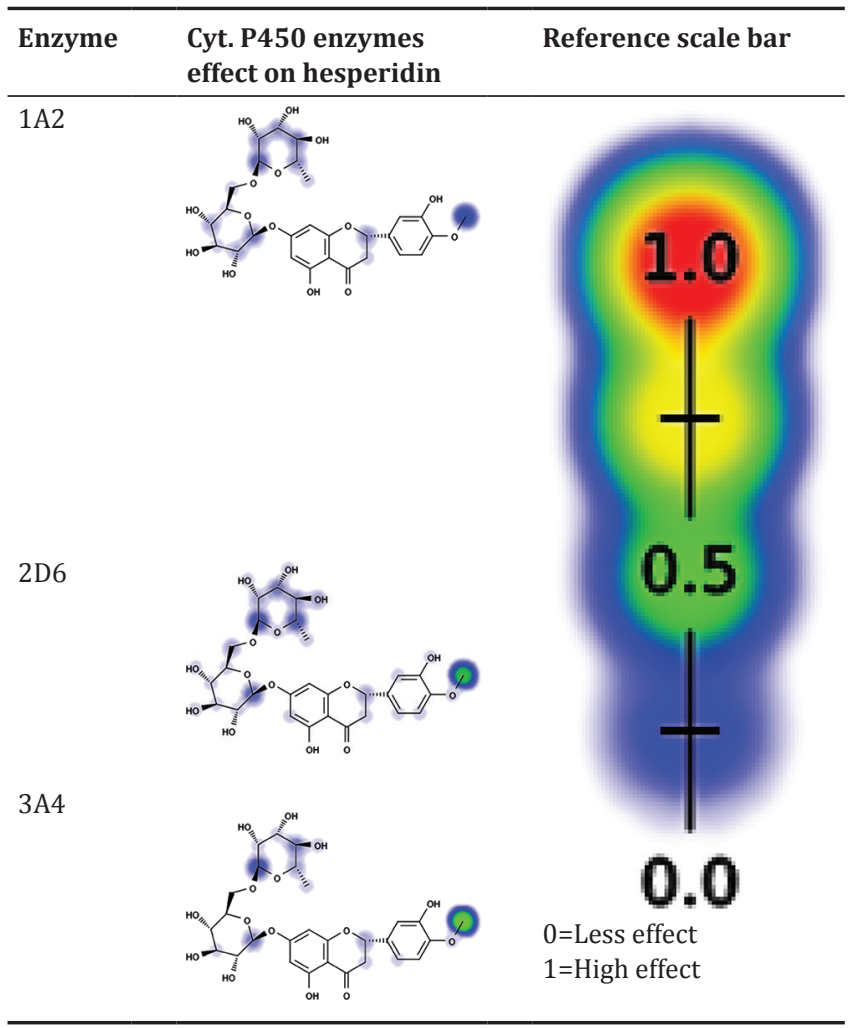

format from MOE2015 software. The three-dimensional (3D) structure was protonated and CHRMM force field used to reduce energy. Followed by preparation of minimized structure using prepares ligand protocol. Docking procedure was done using CDCKER protocol, which is a gridbased molecular docking method that used CHRMM based molecular dynamics scheme to dock ligands into a receptor binding site. The receptor was held rigid while the ligands were allowed to be flexible and during the alteration, each molecule was allowed to produce seven different interaction poses with the protein. Then, docking scores (-CDOCKER interaction energy) of the best-fitted poses with the active site at Aurora-B protein and MST3 protein were recorded.

\section{RESULTS AND DISCUSSION}

Synthesis of HSP 1,3,4-thiadiazole-2-thiol

The newly compound synthesized from reacting HSP with 5-amino1,3,4-thiadiazole-2-thiol as depicted in Scheme 1.

The FT-IR spectrum exhibited the disappearing band of $\mathrm{C}=0$ from $1647 \mathrm{~cm}^{-1}$ and rising new band $1627 \mathrm{~cm}^{-1}$ attributed to $\mathrm{C}=\mathrm{N}$; moreover, new week band was assigned at $2553 \mathrm{~cm}^{-1}$ for stretching of $\mathrm{S}-\mathrm{H}$ band. The ${ }^{1} \mathrm{H}$-NMR spectrum as well was harmonized with the FT-IR spectrum. The ${ }^{1} \mathrm{H}$-NMR spectrum (Fig. 1) exhibited all peaks at their expected region with their expected integration. The EIMs spectrum displayed the molecular ion and the base peak (100\%) as well, all fragments were in agreement with proposed structure. The fragment m/z 116 for $\mathrm{C}_{2} \mathrm{~N}_{2} \mathrm{~S}_{2}{ }^{\cdot+}$ confirms the existence of 1,3,4-thiadiazole-2-thiol part at the structure.

\section{ADMET and carcinogenicity study}

The ADMET and carcinogenicity results are shown in Tables 1 and 2 indicated that the capacity of new synthetic HSP to enter BBB is very low, which give a good pointer that it is safe toward

Table 4: Effect of liver microsomal enzymes on hesperidin derivative

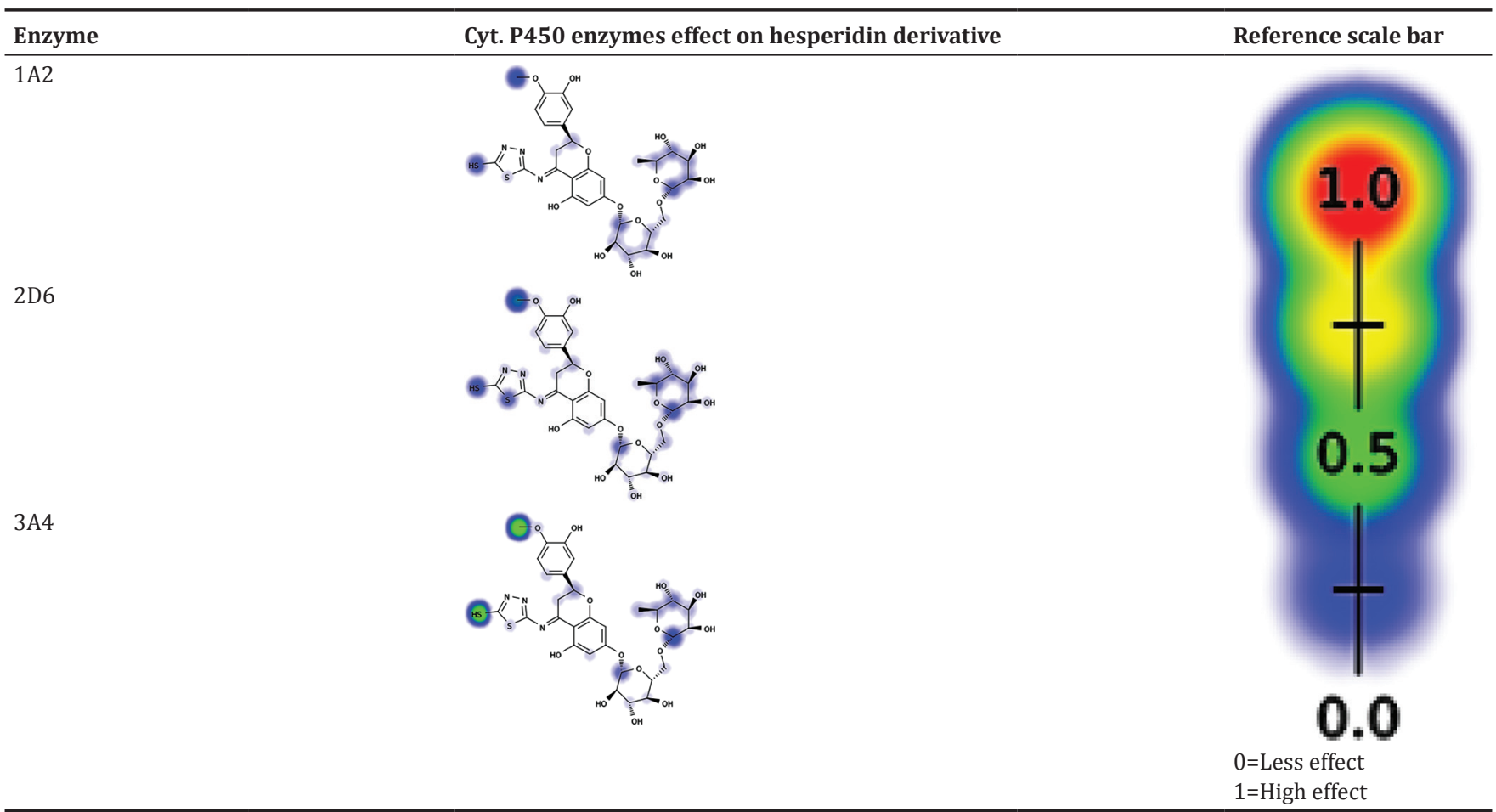

Table 5: Molinspiration bioactivity score v2018.0

\begin{tabular}{llllll}
\hline & $\begin{array}{l}\text { GPCR } \\
\text { ligand }\end{array}$ & $\begin{array}{l}\text { Ion channel } \\
\text { modulator }\end{array}$ & $\begin{array}{l}\text { Kinase } \\
\text { inhibitor }\end{array}$ & $\begin{array}{l}\text { Nuclear } \\
\text { receptor ligand }\end{array}$ & $\begin{array}{l}\text { Enzyme } \\
\text { inhibitor } \\
\text { inhibitor }\end{array}$ \\
\hline Hesperidin & -0.01 & -0.59 & -0.36 & -0.2 & 0 \\
Hesperidin derivative & -0.44 & -1.64 & -1.07 & -1.24 & 0.06 \\
\hline
\end{tabular}

GPCR: G protein-coupled receptors 


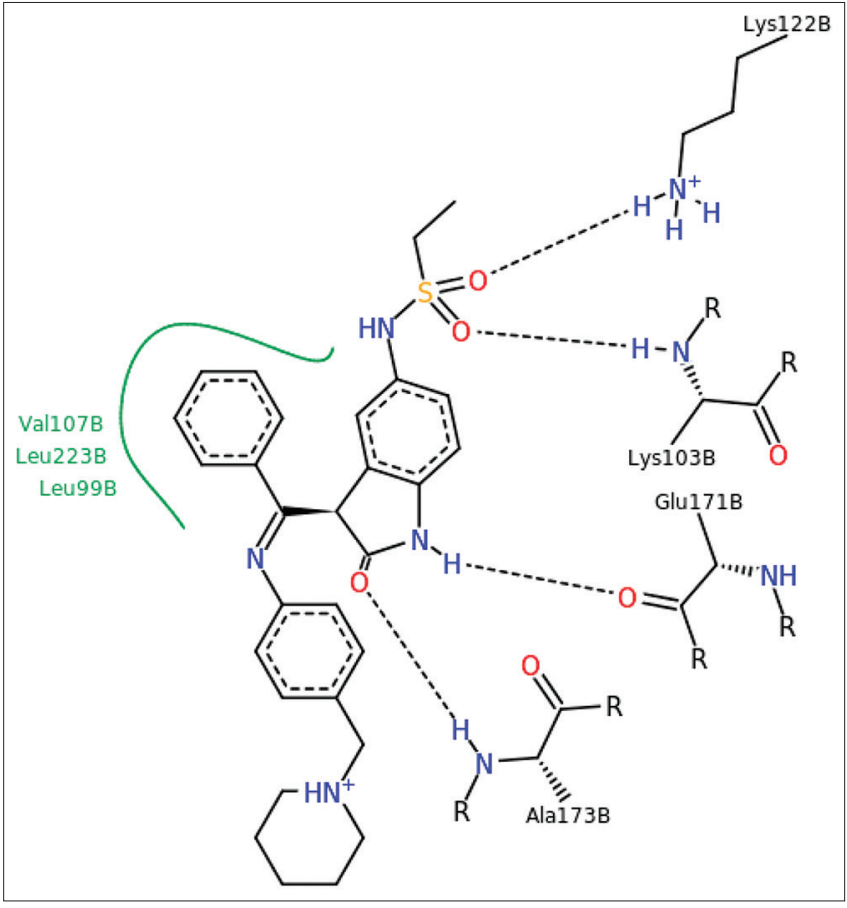

Fig. 3: Binding mode of crystal ligand of Aurora-B protein

Table 6: C $\log \mathrm{p}$, molecular polar surface area, and MV of hesperidin and hesperidin derivative

\begin{tabular}{llll}
\hline Comp. & $\mathbf{C l o g} \mathbf{p}$ & MV & TPSA \\
\hline Hesperidin & -0.55 & 511 & 234.3 \\
Hesperidin derivative & 0.76 & 587 & 255.38 \\
\hline
\end{tabular}

MV: Molecular volume, TPSA: Total polar surface area

central nervous system. The enhancement of absorption is probable to the hydrophobic properties, which increases the lipophilicity so that our derivative HSP was found to be more aqueous soluble. This was confirmed by the human ether-a-go-go-related gene (HERG) results, by which the new HSP gave a negative result compared to the HSP, which gives an inhibitory effect. The inhibitory potency might due to the lipophilicity of compound [11]. Measurement of compound effect on HERG channels function has become essential in development of the safety compounds as it can give information about its possible risks on public health [13].

The plasma protein binding modeling predicts good binding ability of a compound to plasma proteins. It is one of the significant parts in drug safety as it gives an idea about change in volume, distribution, clearance, and half-life [14]. The CYP2D6 model predicts the suppression and non-suppression performance of chemical structure and provides metabolic profile information. CYP2D6 enzyme plays important role in the metabolism of xenobiotic excretion from the body [15]. The result of the present study indicated that the new synthesized compound is non-suppression of CYP2D6; hence, its liver dysfunction effect is low.

Finally, if the carcinogenicity scores close to one the prediction of cancer is high, though if the carcinogenicity scores close to zero, the prediction of cancer is less.

\section{Premetabolism and permeability study}

The 3A4 liver microsomal enzyme has more effect on our compound than do the $1 \mathrm{~A} 2$ and 2D6 enzymes, the most metabolic reaction that can occur is dealkylation of $\mathrm{O}-\mathrm{CH} 3$ then reduction occurs to be $\mathrm{OH}$ group or sulfonation of SH group in thiadiazol ring that is easy to execrate from human body (Tables 3 and 4).

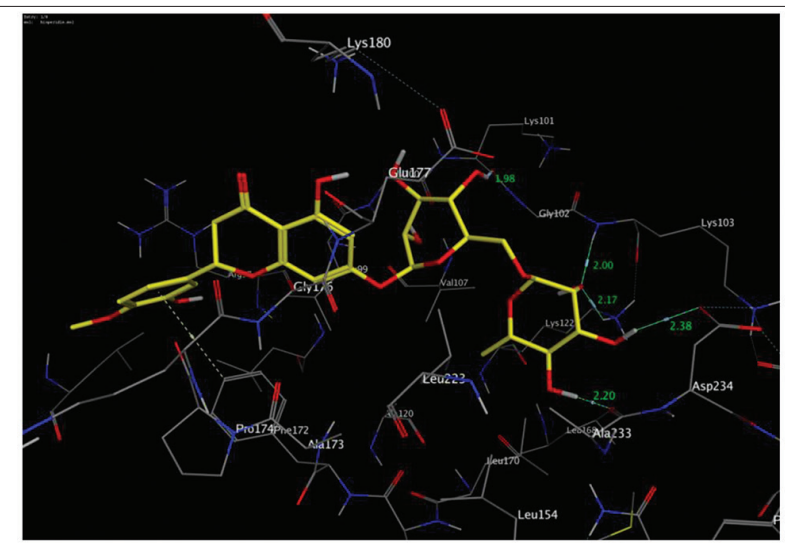

a

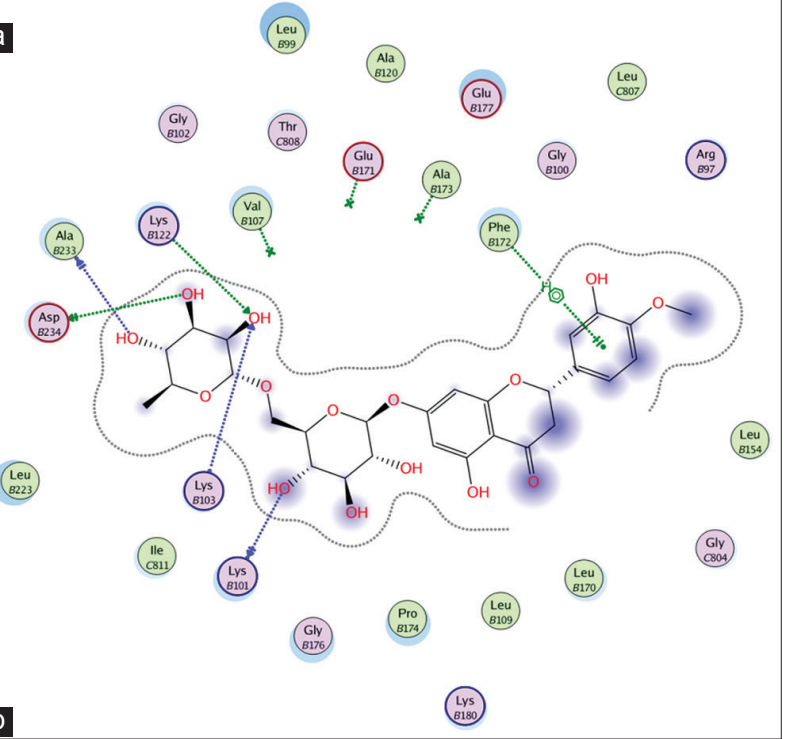

Fig. 4: (a and b) Binding mode two-dimensional and threedimensional structure of hesperidin against Aurora-B protein as potent antioxidative and anticancer

Images below showed the scattering of activity scores with six drug classes compared with those for "average drug-like molecules" (Fig. 2). The higher activity indicated by the large value of the score.

Calculated distribution of activity scores (version v2018.03) for G protein-coupled receptors ligands, kinase inhibitors, ion channel modulators, nuclear receptor ligands, protease inhibitors, and other enzyme targets compared with scores for about 100,000 average drug-like molecules. The score allows efficient separation of active and inactive molecules (Table 5).

The affiliation between the lipophilicity of the HSP derivative compound and their biological activities was done vain the correlation of anticancer (as apoptosis promoter) with the $\mathrm{C} \log \mathrm{p}$ values. By which it expresses the degree of lipophilicity of the chemical compound. The more the value increased the higher lipophilic character of the tested compound. Notably that the $\mathrm{C} \log \mathrm{p}$ values for our synthesized compound were ranging from -0.055 to 0.76 .

These values may explain the difference in their biological activity compared with their lipophilicity. Furthermore, the $C \log p$ values for the compound sat in the ideal range of lipophilicity. Thus, a correlation between the anticancer character of the targeted compound and its lipophilic properties can be suggested. In addition, the TPSA is another key property linked to drug bioavailability; our compound TSPA value range (230-255) indicated good polarity of compound with adequate values of TPSA. Furthermore, molecular volume (MV) descriptor 


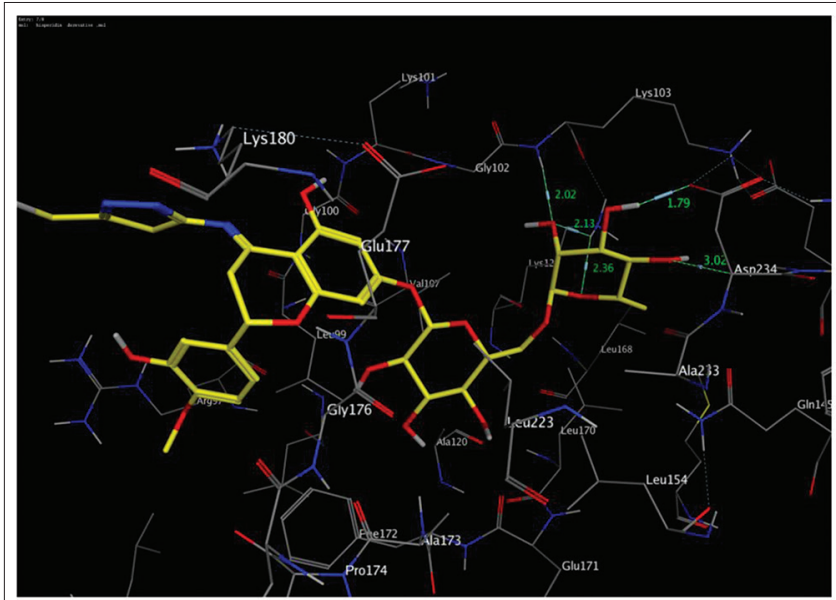

a

$\left(\begin{array}{l}G 1 / 2 \\ \text { (1020) }\end{array}\right.$

Aata

L45

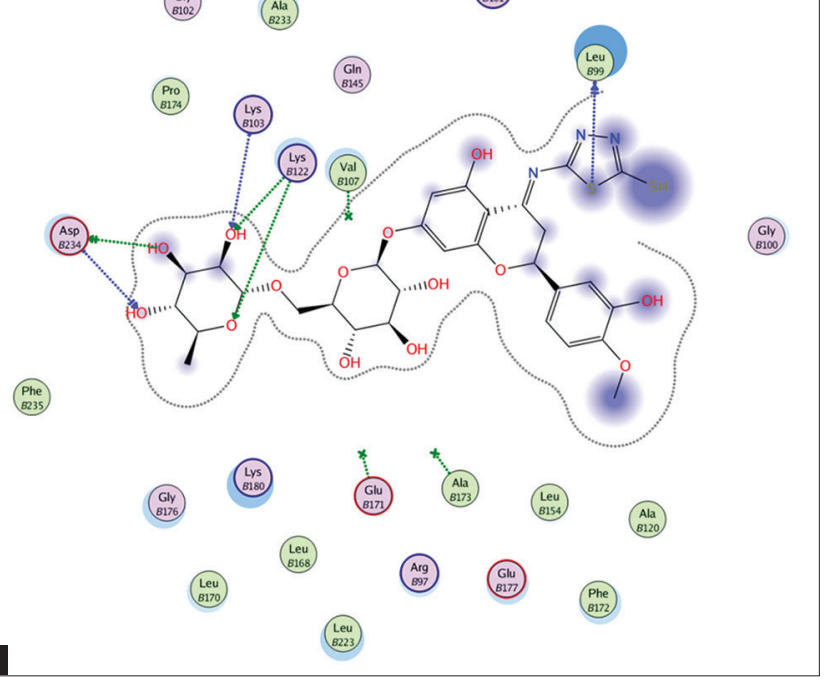

Fig. 5: (a and b) Binding mode two-dimensional and threedimensional structure of hesperidin derivative against Aurora-B protein as potent antioxidant and anticancer

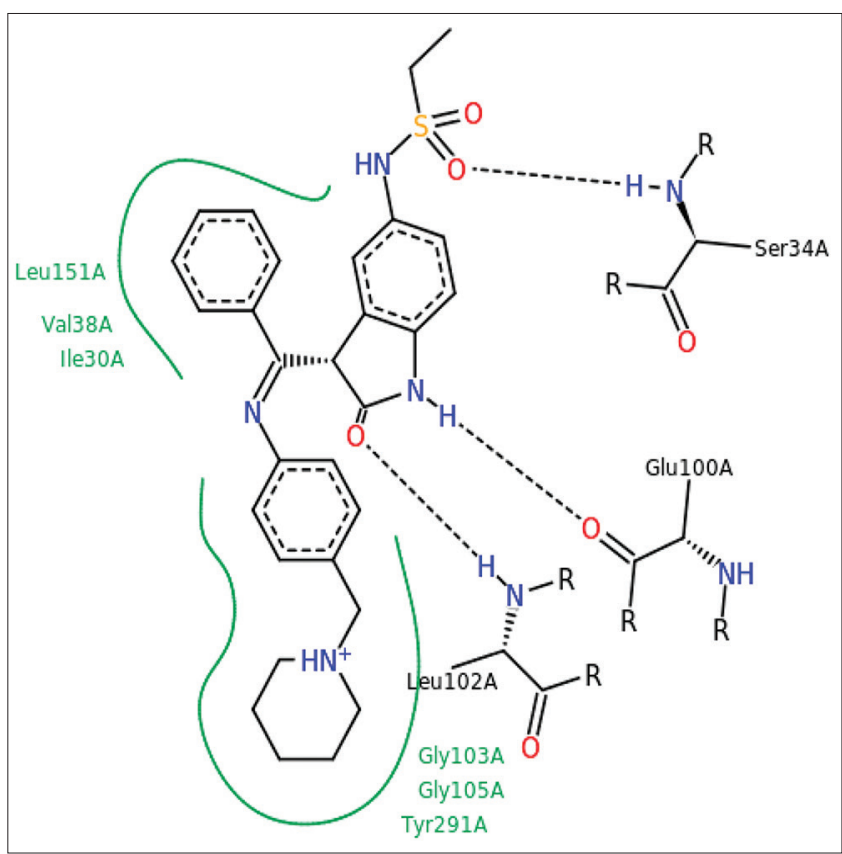

Fig. 6: Binding mode of crystal ligand of MST3 protein

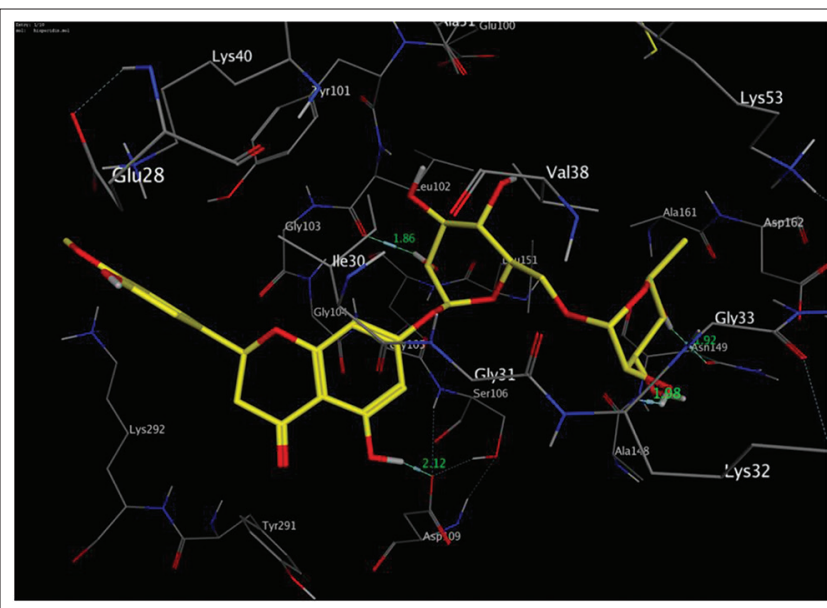

a

(Aa)

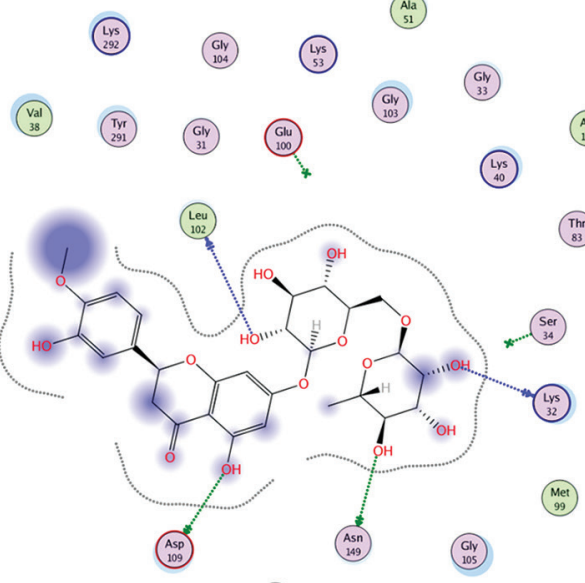

Aat

Thin

Asp

(Leu

(IVI)

$\left(\begin{array}{c}5 e r \\ 106\end{array}\right)$

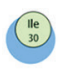

Ala

b

Fig. 7: (a and b) Binding mode two-dimensional and threedimensional structure of hesperidin against MST3 protein as potent antioxidative and anticancer

determines transport characteristics of molecules, such as intestinal absorption. It was noted that the synthesized compound exhibited good MV values, the $C \log p$ values, TPSA, and MV values were calculated using Cheminformatics on the Web (http://www.molinspiration.com) and summarized in Table 6.

\section{Docking study}

The present study suggested that our compound could bind into the pockets of Aurora-B protein and MST3, one close to the Aurora-B site (pocket 1) and the other one close to MST3 site (pocket 2). In this study, processes used to suggest binding mode, affinity, ideal orientation of each docking pose, and binding free energy $(\Delta G)$ of the tested compound with Aurora-B protein and MST3 protein. The grades of interaction energy for the tested compound were in contract with experimental result which showed that our new compound (HSP derivative) are potent inhibitors of Aurora-B protein and MST3 protein when compared to the HSP as antioxidative stress anticancer (apoptosis inducers).

First, the key binding site of Aurora-B protein has been reported, consisting amino acid Lys122B, Lys103B, Glu171B, Ala173B, and other amino acids can form extra bonds as Val107B, Leu223B, and Leu99B (Fig. 3).

The suggested binding mode of HSP showed affinity value of $-8.91 \mathrm{kcal} / \mathrm{mol}$. It indicated five hydrogen bonding with distance range 1.98 and $2.38 \AA \AA$ between $(\mathrm{OH})$ group of (sugar) moieties and residues 


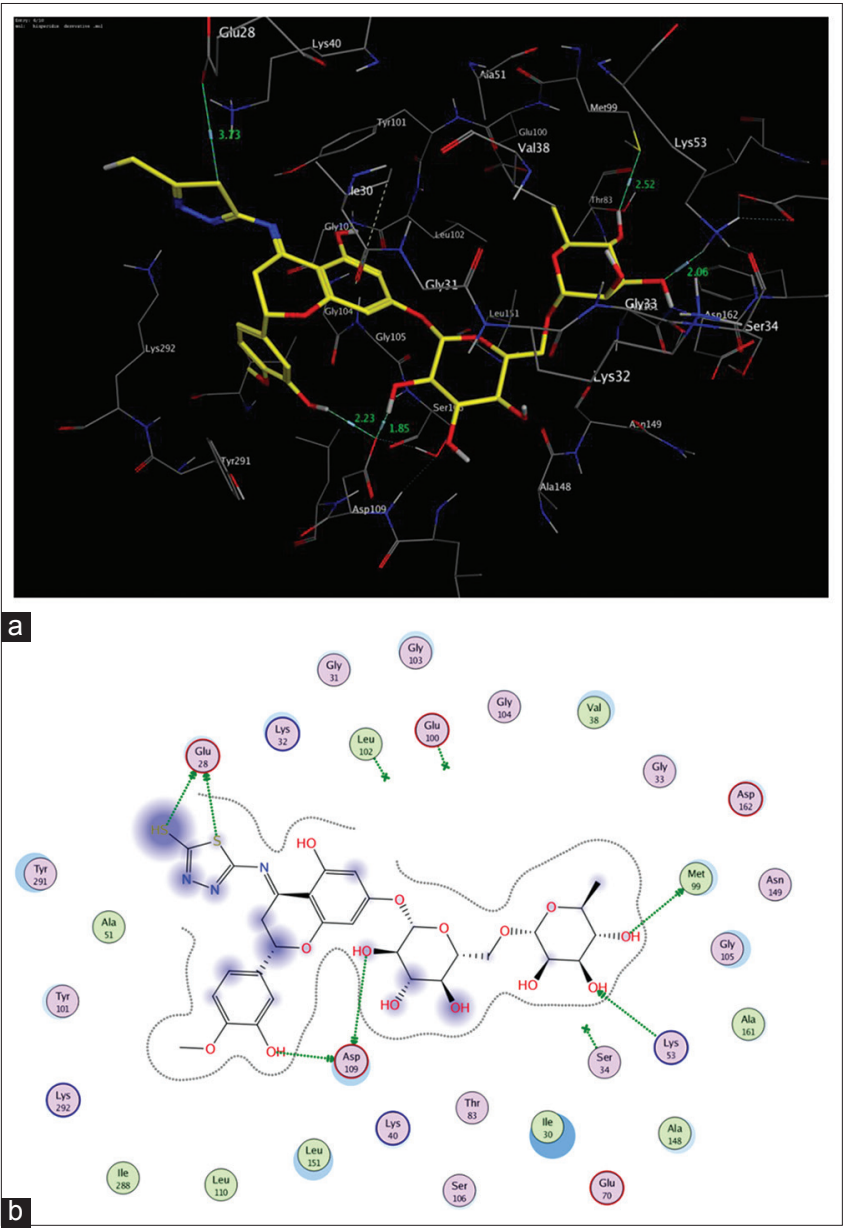

Fig. 8: ( $a$ and b) Binding mode two-dimensional and threedimensional structure of hesperidin derivative against MST3 protein as potent antioxidant and anticancer

of Asp234B, Ala233B, Lys122B, Lys103B, Lys101B, and one Pi-Pi interaction with Phe172B (Fig. 4).

The proposed binding mode of a new compound (HSP derivative) showed affinity value of $-8.41 \mathrm{kcal} / \mathrm{mol}$. It showed six hydrogen bonding with distance range 1.79 and 3.0 Å between OH group of sugar moieties and (S) group of thiadiazole ring against residues of Asp234B, Lys122B, Lys103B, and Leu99B amino acids (Fig. 5).

Second, the key binding site of MST3 protein has been described in the literature, containing amino acid Ser34A, Leu102A, Glu28A, Glu100A, and other amino acids can form extra bonds as Lys32A, Leu151A, Gly103A, Asp109A, Gly105A, and Tyr291A (Fig. 6).

The suggested binding mode of HSP showed affinity value of $-7.61 \mathrm{kcal} / \mathrm{mol}$. It indicated four hydrogen bonding with distance range 1.86 and $2.12 \AA$ between $(\mathrm{OH})$ groups and residues of Asp109A, Lys32A, Asn149A, and Leu102A (Fig. 7).

The suggested binding mode of HSP derivative showed affinity value of $-8.63 \mathrm{kcal} / \mathrm{mol}$. It indicated six hydrogen bonding with distance range 1.85 and 3.73 A between $(\mathrm{OH})$ groups and $(\mathrm{S}, \mathrm{SH})$ groups thiadiazol ring against residues of Asp109A, Lys53A, Met99A, and Glu28A (Fig. 8).

Aurora kinases family (A, B, and C) plays an essential role in mitosis regulation and their overexpression has been associated with tumor cells, thus finding Aurora kinases inhibitors have attracted attention in identifying new anticancer medication [16]. Aurora B involves in several important mitotic phases chromosome segregation and cytokinesis [17]. Furthermore, it has been reported that failure in some cell cycle activity, i.e., cytokinesis and abnormal mitosis exits due to the decreased in Aurora B kinase activity by inhibitors, resulting in the endoreduplication, accumulation of polyploidy cells, and ultimately apoptosis [18,19]. HSP induced apoptosis by inhibition of Aurora kinases and [20].

Development of antitumor drug targeting the serine/threonine kinases family has been studied recently using docking study as an important technique to identify stabilizing drug-target interactions. Moreover, according to the high level of consistency results between the TFBS. Moreover, 3D maps give a good indicator of potency inhibitors against Aurora B kinase for various tumors.

\section{CONCLUSION}

In the present study, a new HSP derivative has been synthesized and characterized successfully and a theoretically promising antioxidant and anticytotoxic active agent introduced. We have shown the detailed binding analysis of 1,3,4-thiadiazol and hydrogen bonds with the inhibitor binding cavity of Aurora B and MST3. This could provide the development of some effective compounds against different diseases. Furthermore, in vivo and in vitro studies are suggested to confirm its biological and pharmacological activity.

\section{ACKNOWLEDGMENT}

The authors gratefully acknowledge Dr. Abdulrahman Mohammed Saleh; Medicinal chemistry and drug design, Faculty of Pharmacy for Boys Al-Azhar University, Cairo, Egypt, for providing computational studies.

\section{AUTHORS' CONTRIBUTIONS}

All the authors have contributed equally.

\section{CONFLICTS OF INTEREST}

The authors declare that they have no conflicts of interest.

\section{REFERENCES}

1. Bohm B. Introduction of Flavonoids. $1^{\text {st }}$ ed. Amsterdam: Harwood Academic Publishers; 1998.

2. Seyoum A, Asres K, El-Fiky FK. Structure-radical scavenging activity relationships of flavonoids. Phytochemistry 2006;67:2058-70.

3. Roohbakhsh A, Parhiz H, Soltani F, Rezaee R, Iranshahi M. Neuropharmacological properties and pharmacokinetics of the citrus flavonoids hesperidin and hesperetin-a mini-review. Life Sci 2014;113:1-6.

4. Al-Rikabi RH, Al-Shmgani HS. Evaluation of hesperidin protective effect on lipopolysaccharide-induced inflammation and lipid peroxidation in BALB/C male mice. Res J Pharm Tech 2018;11:5513-6.

5. Das S, Mandal SK. Current developments on anti-inflammatory natural medicines. Asian J Pharm Clin Res 2018;11:61-5.

6. Majumdar S, Srirangam R. Solubility, stability, physicochemical characteristics and in vitro ocular tissue permeability of hesperidin: A natural bioflavonoid. Pharm Res 2009;26:1217-25.

7. Cao R, Xue Y, Strappe P, Blanchard C, Zhou Z. Natural products derived from tea on the solubility of hesperidin by LC-TOF/MS and NMR. Int J Food Properties 2017;20:5270-8

8. Jakovljevi K, Mati IZ, Stanojkovi T, Krivokua A, Markovi V, Joksovi MD, et al. Synthesis, antioxidant and antiproliferative activities of 1,3,4-thiadiazoles derived from phenolic acids. Bioorg Med Chem Lett 2017;27:3709.

9. Omar YM, Abdu-Allah HH, Abdel-Moty SG. Synthesis, biological evaluation and docking study of 1,3,4-thiadiazole-thiazolidinone hybrids as anti-inflammatory agents with dual inhibition of COX-2 and 15-LOX. J Bioorg Chem 2018;80:461-71

10. Murali A, Shaji A. Synthesis characterization, and evaluation of antibacterial and antidepressant activities of novel tetrasubstituted imidazole derivatives. Asian J Pharm Clin Res 2019;12:93-7.

11. Gill-Lzquicrdo A, Gil MI, Tomas-Barbcran FA. Influence of industrial processing on arrange juice flavanune solubility and transformation to chalcones under gastrointestinal conditions. J Agric food Chem 2003;51:3024-328 
12. Available from: http://www. Molinspiration.com.

13. Goineau S, Legrand C, Froget G. Whole-cell configuration of the patch-clamp technique in the hERG channel assay to predict the ability of a compound to prolong QT interval. Curr Protoc Pharmacol 2012;10:10-5

14. Ghafourian T, Amin Z. QSAR models for the prediction of plasma protein binding. Bioimpacts 2013;3:21-7.

15. Hochleitner J, Akram M, Ueberall M, Davis RA, Waltenberger B, Stuppner $\mathrm{H}$, et al. A combinatorial approach for the discovery of cytochrome P450 2D6 inhibitors from nature. J Sci Rep 2017;7:1-13.

16. Keen N, Taylor S. Aurora-kinase inhibitors as anticancer agents. Nat Rev Cancer 2004:4:927-36.

17. Kaitna S, Pasierbek P, Jantsch M, Loidl J, Glotzer M. The Aurora B kinase AIR-2 regulates kinetochores during mitosis and is required for separation of homologous chromosomes during meiosis. Curr Biol
2002;12:798-812.

18. Hauf S, Cole RW, LaTerra S, Zimmer C, Schnapp G, Walter R, et

al. The small molecule hesperadin reveals a role for Aurora B in correcting kinetochore-microtubule attachment and in maintaining the spindle assembly checkpoint. J Cell Biol 2003;161:281-94.

19. Harrington EA, Bebbington D, Moore J, Rasmussen RK, Nakayama AO, Ajose-Adeogun T, et al. A potent and selective small-molecule inhibitor of the Aurora kinases, suppresses tumor growth in vivo. Nat Med 2004; 10:262-7.

20. Saiprasad G, Chitra P, Manikandan R, Sudhandiran G. Hesperidin induces apoptosis and triggers autophagic markers through inhibition of Aurora-A mediated phosphoinositide-3-kinase/Akt/mammalian target of rapamycin and glycogen synthase kinase- 3 beta signalling cascades in experimental colon carcinogenesis. Eur J Cancer 2014;50:2489-507. 